\title{
Prospects for the Use of Technology of Rotary Steerable Systems for the Directional Drilling
}

\author{
Anton Epikhin ${ }^{1}$, Vitaly Zhironkin ${ }^{1, *}$, and Michal Cehlar ${ }^{2}$ \\ ${ }^{1}$ National Research Tomsk Polytechnic University, 634050, 30 Lenina st., Tomsk, Russia \\ ${ }^{2}$ Technical University in Kosice, Institute of Earth Resources, Faculty of Mining, Ecology, Process \\ Control and Geotechnologies, Park Komenského 19, 042000 Košice, Slovakia
}

\begin{abstract}
In the process of gradual reorientation of the oil industry to the production of heavy hydrocarbons, inaccessible to traditional methods of production, the need arises for the application of modern technological solutions. One of these technologies is directional drilling, which poses new challenges for drilling equipment, such as facilitating sliding - changing the angle of well bore, improving the cleaning of the wellbore, reducing the risks of differential sticking, overcoming resistance during horizontal drilling, etc. A modern technological solution is rotary steerable systems (RSS) representing a new generation of downhole systems used in directional drilling. The article discusses the advantages and disadvantages of RSS technology, its modifications, gives a classification, also provides a comparative analysis of well wiring using rotary steerable systems and, the most widely used, mud motor.
\end{abstract}

\section{Introduction}

The oil industry today faces the challenge of ending the era of light oil. In this regard, an increasing emphasis is placed on the extraction of hard-to-recover reserves, that is, on those deposits where production by traditional methods was unprofitable. Obviously, this would not have been possible without the creation of new technologies that could open the world to unconventional oil (matrix, solid reservoir oil, tight oil). So, in 2010, in the USA, oil production of high-density reservoirs (shale oil) was put into commercial operation. An important role in the transformation of the industry is played by such technology as directional drilling. However, this method of well construction requires accurate calculations and measurements directly during drilling. The borehole trajectory, the presence of rock intermittency in hardness, large vertical deviation together with critical tool loads make well construction more capital-intensive and time-consuming.

\section{Materials and Methods}

The issues of direction drilling are studied by researchers in different countries [1-5]. There are various types of drilling equipment used to drill directional wells. The use of a mud motor

\footnotetext{
${ }^{*}$ Corresponding author: vsz14@tpu.ru
} 
- a volumetric (hydrostatic) machine is widely used. So, by 2010 in Russia, three quarters of the total volume of drilling and repair work was carried out with the help of the mud motors. However, when using this technology for directional drilling, a number of disadvantages arise, such as the inability to achieve uniform bending of the barrel, low penetration rate, risk of sticking, etc. This may be due to the fact that when drilling horizontal sections of the well, resistance forces can increase and reach such values at which the axial load becomes insufficient to overcome the braking of the drill string on the wall of the wellbore, which significantly complicates the drilling process. A modern alternative to mud motor is the technology of rotary steerable systems (RSS), created in the late 1990s. The most important feature and, accordingly, the main advantage of RSS is that this technology provides a directional drilling process along with continuous rotation of the entire drill string, thereby improving cleaning conditions and the quality of the borehole, preventing sticking and spiral twisting of pipes, ensuring the transfer of the necessary load on a chisel to optimize the speed of penetration, save time and cost. In addition, RSS reduces twisting and axial loads, as well as stick \& slip phenomena, compared to directional drilling using mud motors. The use of rotary steerable systems provides the possibility of drilling longer intervals with a uniform diameter of the trunks, which facilitates the descent of the casing string. But for the effective application of RSS it is necessary to pay attention to a number of technical and technological aspects at the design stage.

The advantages of RSS technology are:

- an increase in the mechanical speed of penetration and, accordingly, a decrease in the time of drilling the well, the exception of raising a workable bit for measuring the geometry of the downhole motor;

- improving the cleaning of the well from sludge, reducing the time for flushing before building and lowering and raising operations;

- a decrease in dynamic pressure surges, a decrease in the probability of hydraulic fracturing of rocks;

- improving the quality of the wellbore with minimal micro-curvature, the absence of spiral production due to constant monitoring of the cutting surface of the bit, which allows for successful completion;

- the ability to post complex three-dimensional profiles with a large waste.

The disadvantages include:

- the need to use a top drive;

- high requirements for cleaning mud, low solids and materials to eliminate losses;

- susceptibility to vibration loads;

- the introduction of additional sensors in the drilling system (mud pump discharge line);

- the need to use powerful and reliable pumps;

- the use of expensive bits, specially designed and manufactured for such systems.

History of creation

In 1993, Agip S.p.A. and Baker Hughes INTEQ have begun work on new drilling equipment (Figure 1). For the development, the existing concepts of telesystems and drilling mechanisms were used, on the basis of which, a new system of steerable rotary drilling was designed. It was called the "rotary closed loop system" (RCLS) (Fig. 2), since, having feedback, it was able to provide control of the zenith angle and azimuth directly during drilling. (Fig. 3)

The following design decisions were applied:

1. The hydraulic channel of the two-way communication "well head - bottom hole", which allows to control the system directly in the process of drilling.

2. To change the azimuth and zenith angle during rotation of the drill string, a non-rotating guide block was designed, in which automated control systems were built that did not require intervention from the surface. 
3. Logging while drilling (LWD) module [6] containing various sensors and sensors located in the immediate vicinity of the bit, which allow for accurate geosteering and logging.

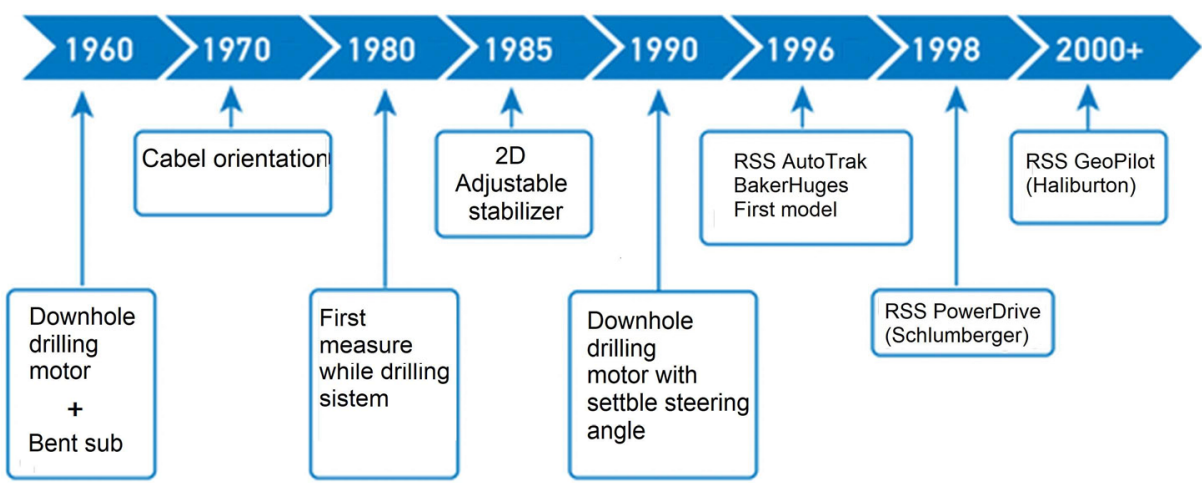

Fig. 1. Evolution of directional drilling technology [7].

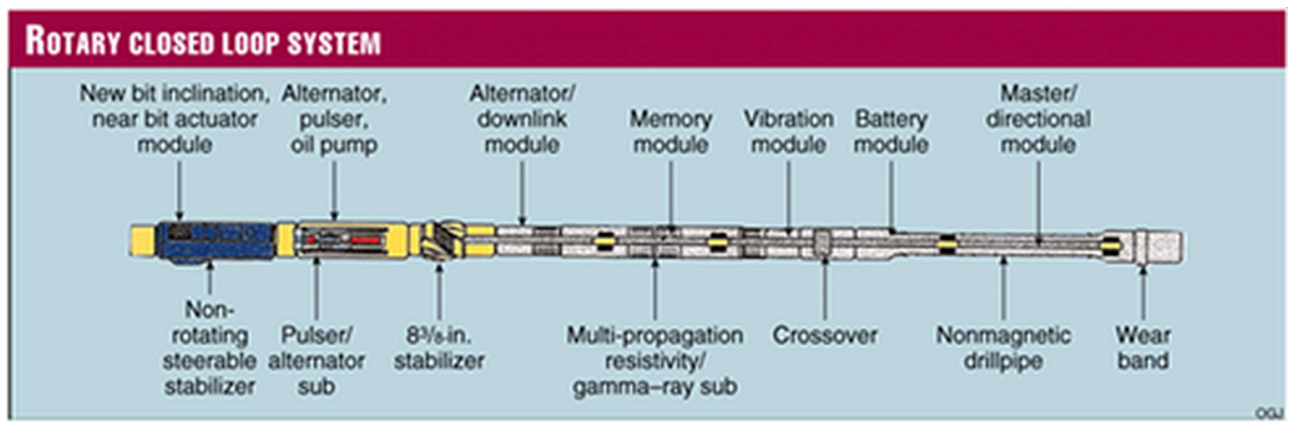

Fig. 2. The composition of the "rotary closed loop system".

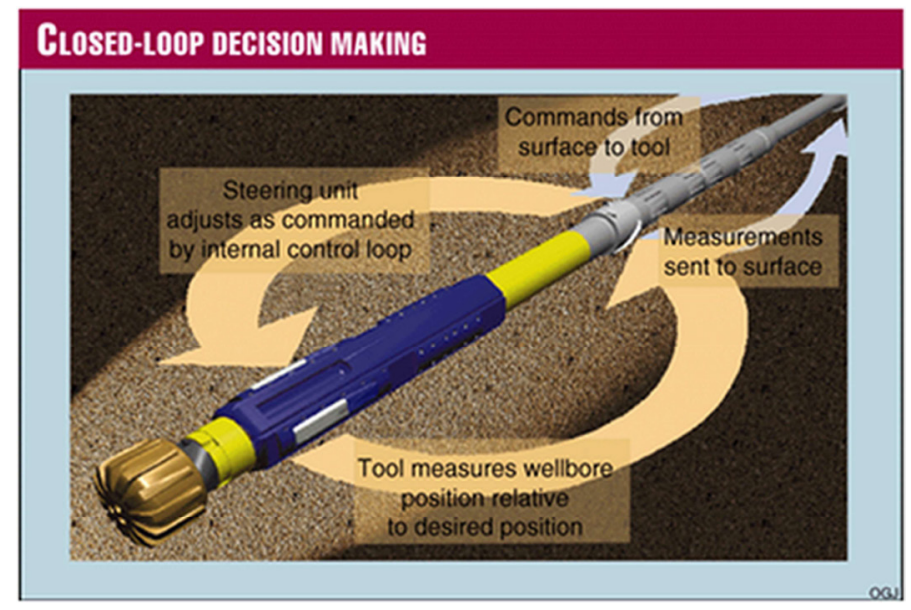

Fig. 3. System operation scheme.

Classification 
Rotary steerable systems according to the method of controlling the displacement of the bit relative to the axis of the well can be divided into two main types.

"Push the bit" - repulsion from the well wall of the whole arrangement or its greater part relative to the axis, which causes pressure on the side surface of the bit in a certain direction. This type includes AutoTrak Baker Hughes INTEQ and Schlumberger PowerDrive.

The principle of operation of the RSS type "Push the bit"

This type of system consists of a non-rotating base unit, a drilling process control unit, and a measurement while drilling (MWD) telesystem module. The base unit includes navigation sensors, a distributing valve and guide vanes. The control unit for the drilling process includes a downhole computer and a turbine generator or lithium batteries. During drilling, the downhole computer checks the design data loaded into it with the values coming from the MWD module.

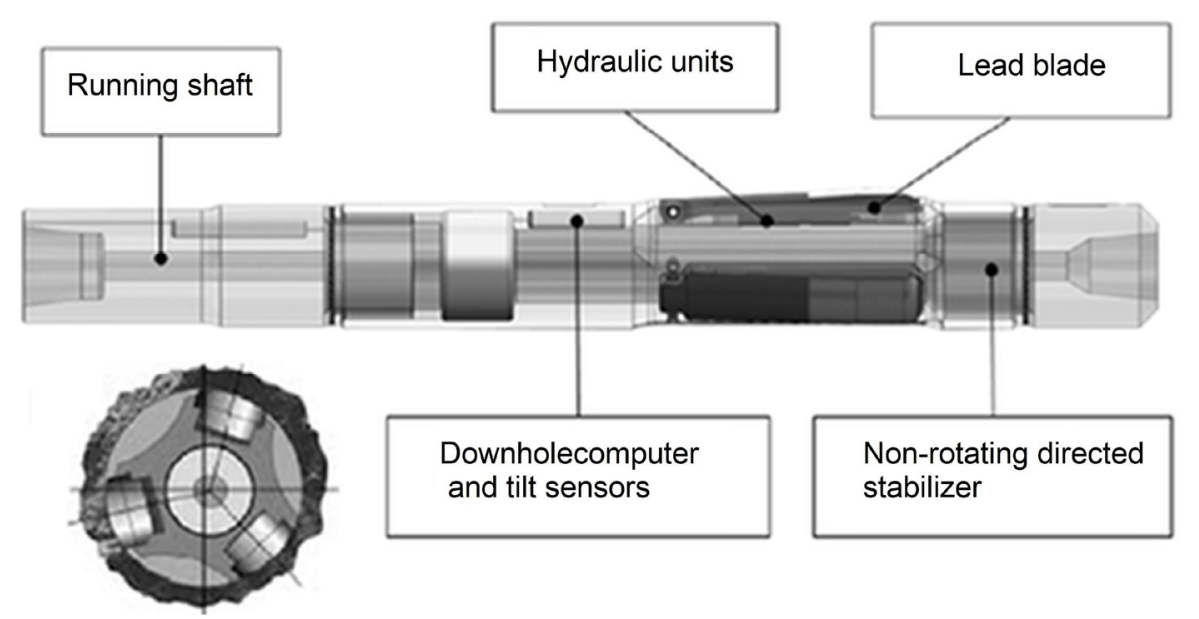

Fig. 4. RSS type "push the bit".

If there is a need to change the drilling path, the downhole computer, using navigation sensors, transmits information to the distributing valve, which directs the hydrodynamic energy of the drilling fluid to the guide blades that extend from the body. As a result, the entire assembly is repelled from the well wall in a given direction.

"Point the bit" - bit positioning. This is achieved by shifting the drive shaft relative to the layout, or by changing its curvature, which causes a change in angle. This type includes: "Geo - Pilot" from Halliburton Sperry Drilling Services, "Well - Guide" from Gyrodata Western Hemisphere [8]. Also referred to as "point the bit" is the Dart system of Andergauge Drilling System.

The principle of operation of the RSS type "Point the bit"

This type of system is a hardware-equipped, over-bit stabilizer consisting of three main components (Figure 5), including a rotating mandrel (drive shaft), an eccentric inner sleeve, and a weighted non-rotating outer case. The tool works by controlling the direction of the eccentric inner sleeve, which biases the mandrel and, accordingly, the bit in a given direction. 


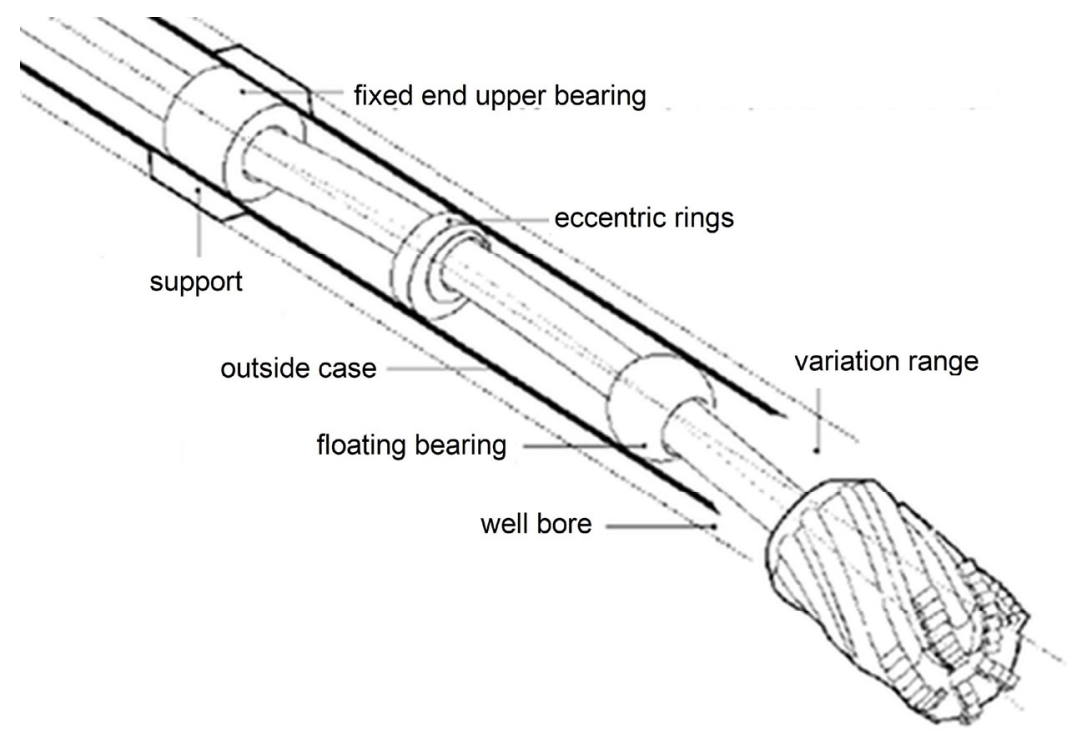

Fig. 5. RSS type "Point the bit".

The location of the outer casing is constantly monitored by a computer that controls the tool and automatically corrects the position of the eccentric inner sleeve to maintain the proper bit orientation.

The rotation of the inner sleeve in order to change the orientation of the bit is carried out by a DC motor with an ultrahigh torque, powered by a lithium battery or a turbine generator. Model range RSS

The RSS models of the "Push the bit" type include the following: "AutoTrak" from Baker Hughes, "PowerDrive" from Schlumberger, "Pathmaker" from Pathfinder Energy Services, domestic prototype RSK-8.75BS.

Species of Point the bit RSS modifications are Geo - Pilot from Halliburton Sperry Drilling Services, Well-Guide from Gyrodata Western Hemisphere, Dart from Andergauge Drilling System, PowerDrive from Schlumberger, Revolution from Weatherford International and domestic development of RSS-GM195.

RSS application.

Modern high-tech equipment significantly increases the efficiency of construction of complex wells, and also makes it possible to drill wells longer than $12 \mathrm{~km}$ with an extremely large deviation from the vertical.

In the USA, about 180 thousand meters (about 100 wells with a horizontal section of the trunk) were drilled at the Alpine field of the Northern slope of Alaska using rotary steerable systems. The bore diameter of these wells ranged from 120.6 to $222.2 \mathrm{~mm}$. In general, nearly 300 thousand meters were drilled in US fields in wells with large deviations from the vertical bottom using RSS, the average depth of the wells was $2100 \mathrm{~m}$, and the deviation was from 2700 to more than $6000 \mathrm{~m}$. Practical experience in using RSS is not only extensive in the USA and other countries, but also in Russia.

In September 2009, the first pilot project for well construction using RSS systems was launched at the Verkhnechonskoye field, which involved the drilling of four horizontal sections with a diameter of $152.4 \mathrm{~mm}$. The average mechanical penetration rate using RSS at four wells was $16 \mathrm{~m} / \mathrm{h}$ (a record of $21.85 \mathrm{~m} / \mathrm{h}$ ), which is twice as high as when using mud motors. This allowed to reduce the drilling cycle of horizontal sections by three days up to 3.62 days. In addition, the use of RSS made it possible to open the reservoir more efficiently with reaching the effective horizontal section length of up to $70 \%$, while in wells 
drilled using the mud motor, this figure is only $30 \%$. And 9 out of 10 top-super-deep wells in the world were drilled in the Sakhalin-1 project using RSS.

According to the Russian central dispatch control of the fuel and energy complex [9], the volume of drilling using RSS in Russia in 2014 amounted to 210 horizontal wells. Mainly RSS was used to drill the bottom of the section under the production casing and horizontal sections. According to the expert assessment of the Russian journal of the oil and gas industry ROGTEC [10], by 2020 the growth in drilling of horizontal wells using RSS up to 2000 wells $/$ year is predicted.

World leaders in the production of RSS are companies: Baker Hughes, Schlumberger, Halliburton, Weatherford. At present, in Russia it is these four companies that provide the full range of high-tech services RSS + MWD / LWD. Many small companies have their own developments of RSS: Aps Technology, Gyrodata, National Oilwell Varco, Scientific Driling, Smart Drilling, etc. Russian manufacturers are also developing their own RSS models. However, in 2015, only two manufacturers: Concern Elektropribor and NPP Burintekh, crossed the stages of conceptual development and design and were able to enter the well tests of prototypes of the first domestic RSS. After a series of tests, the models were not received in mass production and were sent for revision. Companies such as Tyumen Drilling Company, Perm Oil Engineering Company, Integra Group of Companies and some other companies have voiced their intentions to develop RSS, but so far the work is at the stages of conceptual development and design.

\section{Results and Discussion}

Comparison of hole making using RSS and mud motors.

Drilling long horizontal sections using a mud motor is a very difficult task, as it becomes more difficult to control the position of the engine deflector as the length of the section increases. When sliding with the help of the mud motor, the drill string does not rotate, the drilling fluid near the lying wall is in a semi-static state, therefore, drill cuttings are not properly brought to the surface and can accumulate in the form of a "sludge bed", provoking sticking. When pushing a bit on a horizontal section with an engine without rotating the column, the resistance force increases, thereby complicating the drilling process. In wells with large deviations from the vertical, control becomes more complicated, which leads to both problems in maintaining the required direction and costly drilling due to the complicated installation of the downhole motor deflector.

The use of RSS allows to solve these problems. Constant rotation of the system prevents the accumulation of sludge and the occurrence of differential sticking. The slide mechanism is simplified, since the system is controlled by telemetry using special ground equipment, which allows to accurately and quickly set the trajectory. Another advantage of RSS over mud motor is that rotary steerable systems together with tools for LWD provide excellent azimuthal images of the wellbore and high-precision logging data due to the smooth and accurate diameter of the well. Higher-quality log data allows geophysicists to perform geosteering in low-power formations. Whereas, to obtain the exact azimuthal density and resistance of the barrel using geosteering while drilling with mud motors is impossible due to the lack of rotation during sliding. It should be noted that, as the length of the wellbore increases, it becomes more difficult to set the correct rotation speed in the well for programming the rotary steerable system to drill in the required direction. Another disadvantage of RSS is the high cost. Therefore, often Russian companies use both technologies for the construction of one well. Mud motor for drilling vertical and inclined sections and RSS for laying horizontal sections. Thus, RSS can increase the speed of penetration, improve wellbore cleaning, provide smoother trunks, precise well placement and high-quality logging data along with higher wellbore quality and reduced overall costs. 


\section{Conclusion}

Consequently, we considered the technology of rotary steerable systems, its classification and modifications. Based on the presented data on the operation of this technology in Russia and in the world, we can conclude that the technology is widely used for drilling directional wells and individual horizontal sections of wells.

The following positive aspects of their application for the construction of oil and gas wells in comparison with mud motors were identified according to the results of the analysis of the practical application of rotary steerable systems:

- Improving the quality of the well being constructed with subsequent facilitation of the casing string descent;

- Reduction of drilling time;

- Improving the location of the wellbore in the reservoir, which allows to increase the flow rate of the well;

- The possibility of drilling wells with a large deviation from the vertical and the construction of long horizontal sections of the trunk.

Given the current trend in Russia towards import substitution, Russian manufacturers made attempts to create their own rotary steerable systems, however, despite the fact that some companies were able to switch to well testing, their products have not been delivered to the drilling equipment market so far.

\section{References}

1. J. Pinka, B. Jágerová, M. Mihočová, Acta Montanistica Slovaca, 11:1, 137-139 (2006)

2. S. Bednarz, Acta Montanistica Slovaca, 9:3, 152-155 (2004)

3. J. Pinka, J. Lumtzer, J. Badran, Acta Montanistica Slovaca, 1:4, 289-295 (1996)

4. S. Bednarz, J. Artymiuk, M. Capik, E. Tasak, Acta Montanistica Slovaca, 11:1, 10-15 (2006)

5. R. Wiśniowski, S. Stryczek, J. Ziaja, Acta Montanistica Slovaca, 11:1, 229-235 (2006)

6. Scientific drilling international company. URL: https://scientificdrilling.com

7. Scientific and technical center Gazprom-neft'. URL: https://ntc.gazprom-neft.ru

8. The Gyrodata company.URL: https://www.gyrodata.com

9. Russian central dispatch control of the fuel and energy complex. URL: http://www.cdu.ru

10. Russian journal of the oil and gas industry. URL: https://rogtecmagazine.com 